

\title{
Jaime Fernandes Simões e a construção de narrativas sobre a art brut em Portugal
}

\author{
Jaime Fernandes Simões and the art brut narrative constructions in \\ Portugal
}

\section{Dra. Stefanie Gil Franco*}

\begin{abstract}
Resumo
Este artigo narra a história de Jaime Fernandes a partir de imaginários que se formam em torno da noção de art brut, conformando-Ihe qualidades específicas enquanto sujeito louco e artista. Neste sentido, trabalhase com os discursos produzidos pela crítica de arte portuguesa, em especial entre os anos de 1970 e 1980 do século XX, em encontro com as teorias psiquiátricas que fundamentam noções e qualificativos para as expressões dos sujeitos asilados. $O$ caso de Jaime Fernandes é peculiar no sentido em que dá origem a estas discussões em Portugal, sendo ele considerado o primeiro grande artista descoberto nos termos da art brut no país. Propõe-se, sobretudo, conhecer o sujeito Jaime Fernandes a partir do cruzamento destes discursos e proposições conceituais, colaborando numa perspectiva mais ampla para o debate de noções como art brut e outsider art.
\end{abstract}

\section{Palavras-chave}

Art brut. Arte e loucura. Psiquiatria. Jaime Fernandes. Portugal.

\begin{abstract}
This article describes the history of Jaime Fernandes from the imaginary formed around the notion of art brut, which conformed to him specific qualities as a mad subject and an artist. In this sense, the article analyses the discourses produced by art criticism in Portugal, especially between the 1970s and 1980s, according to psychiatric theories that underlie notions and qualifications for the expressions of the asylum subjects. The case of Jaime Fernandes is peculiar in the sense it gives rise to these discussions in Portugal, since he was considered the first great artist discovered under art brut in the country. Above all, It is proposed to know the subject Jaime Fernandes from the intersection of these discourses and conceptual propositions, collaborating in a broader perspective to the discussion of notions as art brut and outsider art.
\end{abstract}

\section{Keywords}

Art brut. Art and madness. Psychiatry. Jaime Fernandes. Portugal. 
Interessou-me a vida de um homem e, sem lamechice, pareceu-me que só poderia interessar outras pessoas se pudéssemos converter esteticamente a vida deste homem, dado que por ele, por si, já não se podia defender ou atacar, ou até nem Ihe interessaria (António Reis, 1974)1.

Este artigo tem por objetivo apresentar Jaime Fernandes a partir das narrativas que se formam em torno de sua produção artística e de sua personagem, surgidas entre os emblemas da art brut e do cinema experimental português. Apenas para iniciar: Jaime esteve por trinta anos em um hospital psiquiátrico, em Lisboa, onde já no final de sua vida produziu uma série de desenhos feitos, principalmente, em caneta esferográfica. Muito pouco se sabe da sua história fora do hospital, e mesmo sobre os anos em que esteve recluso há poucos documentos. Das raras notícias que se conhece sobre a vida de Jaime, parte delas foi publicada na Raw Vision Magazine, pelo investigador português João Pedro Fróis:

Jaime Fernandes came from peasant stock, from a village in the hinterland of Portugal, and he lived a life that was common for small crop farmers whose livelihood depended on weather each year's harvest was good or bad. The first of three children born to farmers Joaquim Fernandes and Maria de Jesus, he was born on May 8, 1899, in Barco, a small village of Covilhã district some 300 kilometres north of Lisbon. In 1923, he married Evangelina Delgado, who bore him five children... (Fróis, 2016a: 28)².

Segundo a ficha do paciente que consta no livro de entrada do Manicômio Miguel Bombarda ${ }^{3}$, Jaime Fernandes possuía uma "esquizofrenia processiva" causada por "ordem moral", com entrada hospitalar em 7 de janeiro de 1938. Nesta ficha não está preenchida a data e a causalidade de sua morte. Sabe$\mathrm{se}^{4}$, no entanto, que Jaime esteve internado por 31 anos, que faleceu em 1968 e que apenas nos últimos anos da sua vida começou a desenhar. Boa parte dos seus desenhos foram doados, por ele, aos enfermeiros e médicos e, pelo que consta nas histórias narradas, muitos se perderam. Sem pretender remontar a trajetória de vida de um artista descoberto em um manicómio, a proposta deste artigo é, antes, tratar das narrativas que compõem a sua história a partir de um imaginário entre o ser "esquizofrênico" e o artista brut ou outsider. Antes de tudo, é preciso saber que Jaime Fernandes é conhecido como a primeira grande descoberta da art brut em Portugal, já nos anos de 1970 - trinta após a criação do conceito ${ }^{5}$.

Mais precisamente, sua história passa a ser conhecida com a estreia do filme Jaime (1974) de António Reis (1927-1991) e de Margarida Cordeiro (1939-)6. O curta-metragem, com duração de pouco mais de 30 minutos, inaugura o universo de Jaime Fernandes numa arte de conceitos, por assim dizer. Isso porque os diretores não pretendiam narrar os delírios do sujeito Jaime como um universo ingênuo ou inócuo em relação à sua doença. $O$ filme retrata-o de modo a tornar a imagem imperante sobre 0 conteúdo, carregada de poesias e planos não lineares. Nas palavras de Eduardo Prado Coelho (19442007), a forte presença da música moldada junto à imagem é

o que impede o filme de deslizar para qualquer das suas eventuais perversões: fosse, talvez a mais óbvia, a de uma denúncia das condições hospitalares (que está presente, mas rasurada como formulação ideológica); ou então a uma possível tendência para equacionar em termos pesadamente teóricos a relação entre a arte, o espaço da criação e a loucura (...) digamos que toda a sorte do filme se concentra na relação que Jaime teve com a sua sorte, e, por isso o filme desaba sobre nós próprios e a nossa inevitável relação com a sorte que nos cabe (Coelho, 1983: 64). 
O filme produz uma poética corporificada pelas linhas de Jaime que se encontram com cenas um tanto confusas da vida campestre e da vida hospitalar, ambientando a sua trajetória no tempo e no espaço. Compreende-se pelas palavras de Margarida Cordeiro que a proposta do filme é dar corpo à história de um artista sem a necessidade de escavar verdades não vistas:

\begin{abstract}
Não o conheci. Vi na parede um desenho a esferográfica - arte psicótica -, apercebi-me de que não era uma reprodução. $E$ encetei numa busca que nos fez conseguir uma centena de desenhos, a lápis, a mercúrio cromo e mesmo outros materiais. Ele aproveitava todo material que lhe davam, até miolo de pão. 0 Jaime teve uma psicose, não havia os medicamentos que hoje dispomos, viveu ali internado trinta e tal anos e só no fim da sua vida começou a desenhar. Na terra nunca tinha desenhado, tal como pudemos concluir da investigação que fizemos - ainda existe a viúva, os filhos, mas realmente a sua obra pictórica só sucedeu naquela ocasião. E era uma centena e tal de desenhos. Quando eu entrei para o Hospital, ele tinha morrido um mês antes. Fotografia só conhecemos duas uma, ele a entrar para o Hospital, e outra, já muito idoso. No filme aparece uma no princípio e outra no fim. Filmamos na terra dele e depois no Hospital. Não pudemos falar do homem, fizemos um filme à volta do Jaime e daquilo que ele tinha deixado (...) Quando eu cheguei aqui no Hospital não havia tratamentos modernos, 0 atendimento de Jaime era mera contenção física. O Jaime tinha passado de mão em mão e eu encontrei a história médica dele. (...) Repare, não podendo abordar o homem, não podendo abordar médicos ou enfermeiros que dessem um testemunho válido, nós utilizámos o material que ele deixou, os lugares onde ele viveu e um pouco da família (a esposa) e o Rio Zêzere. E fizemos uma coisa o mais honesta possível, sem estar a "puxar" pela análise psiquiátrica. Foi o respeito pelo doente, pela pessoa. Um respeito por um artista. (Cordeiro apud Moutinho; Lobo, 1997: 16)
\end{abstract}

Unindo o doente, o sujeito e o artista, compreende-se que Reis e Cordeiro propunham "complexificar 0 real" (Ibidem: 15) a partir da filmagem de realidades distintas, todas elas cotidianas em sua natureza mais vulgar, mas multifacetadas no desencadeamento das imagens, fruto de uma estética por vezes chamada de neorrealista, experimental ou mesmo novo cinema. Ainda na entrevista, Margarida Cordeiro diz que o maior erro do cinema é "simplificar o real" e que seu papel deveria ser o de criar realidades distintas: "pelas imagens, pelas cores, por tudo" (Ibidem). A realidade de Jaime é em si complexa em seu conteúdo: um doente mental desenhador, preso há anos em um hospital psiquiátrico, com uma história de vida pouco conhecida, mas cheia de fantasias concretizadas nos desenhos. Contudo, ainda, a proposta do filme de "complexificação" da forma narrativa faz criar uma realidade paralela ao universo de Jaime. António Reis complementa a descrição de Margarida Cordeiro ao dizer que não se pretendia com o filme a produção da vida de um pintor nem um filme sobre artes plásticas: "digamos, portanto, que a fita é um poema plástico e humano8" (Reis apud Moutinho; Lobo, 1997: 242).

Com esta narrativa sobre um "artista de gênio", como o chamou Reis, Jaime fora projetado ao mundo como um autêntico mestre da art brut, pois que carregava os elementos fundantes de tal categoria: "(...) E a sua estética fauve ou expressionista, se não foi contemporânea desses movimentos europeus, também nada Ihes deve. O seu tempo histórico e psicológico outro era. Era outro o seu espaço de gruta, subterrâneo ou sideral, com nuvens onde viajavam, sonhavam e sofriam, 1000 homens dentro" (Ibidem: $247)^{9}$.

Jaime escreveu e desenhou, conforme já foi mencionado, apenas nos últimos anos de sua vida hospitalar. Inúmeros textos e desenhos, na maioria em grafite ou esferográfica. Os desenhos são feitos de rabiscos, linhas entrecruzadas, formando animais por vezes com características humanas. Outros são homens, alguns com os braços colados ao corpo, estáticos, todos com os olhos bem abertos e a silhueta bem demarcada. De sua escrita, também presente no filme como imagem poética, percebe-se 
algumas particularidades como a repetição da letra "z" ao final de muitas palavras e uma grafia muito adornada e uniforme (figs. 1 e 2). 0 filme traduz algumas destas escritas, dando-lhes destaque à formação de pequenas frases poéticas, tais como "8 vezes Jaime morreu cá" ou "Ninguém só eu"10:
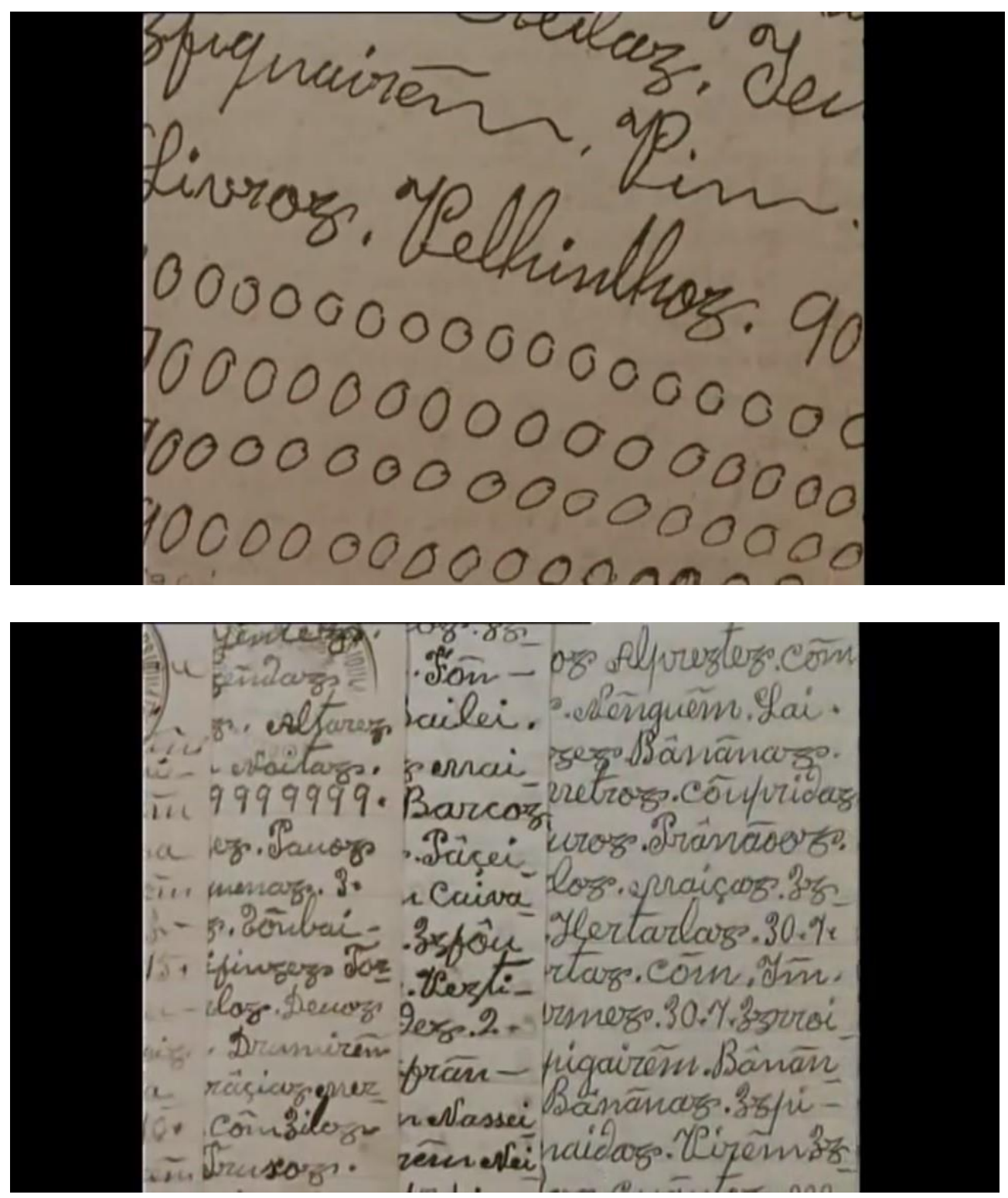

Figs. 1 e 2. Print screen de frames do filme Jaime. António Reis e Margarida Cordeiro, 1974.

A linguagem cinematográfica de Jaime é rude ou, como Reis afirma, possui um "aspecto descascado" (Reis apud Moutinho; Lobo, 1997: 248) e colabora para o efeito de apresentar um artista outsider. 0 parecer publicado por Carlos Paredes reflete bem este resultado:

Porque se empenhou a natureza em conceder os dons da criação, em tão elevado grau a um homem de idade avançada e com o cérebro doente? Porque a capacidade de criar nos aproxima mais da razão da inteligência do que da inteligência em si mesma. Pela inteligência comum organizamos a matéria a partir do cérebro (...). Estes dois tipos de inteligência são interdependentes num mesmo indivíduo, e toda a gente os utiliza na sua 
experiência com a vida. Nos artistas, porém, a inteligência criadora apresenta-se de tal forma aguçada e activa que o equilibrio entre as duas foge a todas as regras. Pode-se, assim, explicar-se que Jaime, com a sua inteligência comum diminuída, tenha libertado, por outro lado, as suas excepcionais capacidades criadoras (Paredes apud Moutinho; Lobo, 1997: 139).

Passamos, sobretudo, a conhecer um pouco mais da história de Jaime, de sobrenome Simões Fernandes, pelas críticas e pela projeção pública que o filme aos poucos vai alcançando. Tal como descrevi acima, Jaime, por consequência de sua forma experimental, faz surgir um artista já impregnado de conceitos e qualidades estéticas. Percebe-se, também, tanto pelo filme quanto pelos críticos uma série de apropriações não questionadas ou bem pouco questionadas de termos psiquiátricos e de uma clássica imagem do "artista louco", em qualificativos como: "artista demente", "obsessão", "qualquer coisa de ingênuo e puro", "artista de gênio", "gênio", e outro "relâmpagos geniais", "ignorante e louco", "conflitos e problemas interiores", "sem nexo aparente"11 e assim a continuar. Enfim, pelo filme não conhecemos um sujeito com uma trajetória de vida, mas uma "poética" que envolve Jaime Fernandes e o universo de um hospital psiquiátrico.

Não é possível, entretanto, pensar na proposta de Reis e Cordeiro sem entrecruzar alguns acontecimentos históricos da psiquiatria, porque eles são formadores de enunciados que possibilitam tanto Jaime, o filme, quanto Jaime Fernandes, o artista brut. Mais especificamente, o artista é descoberto num momento em que a psiquiatria em Portugal começava a repensar o espaço asilar ou manicomial em detrimento de outros tipos de tratamento - a lembrar que a psiquiatria no país seguiu historicamente uma vertente organicista e que os modelos de ruptura psiquiátrica, ou a antipsiquiatria, foram muito contestados e contrariados:

Numa época em que se constituiu como ordem-do-dia a polémica entre o psiquiatrismo tradicionalista e a antipsiquiatria - época em que, portanto, em determinado sector se pretende defender a ideia de que o 'doente' não deve ser segregado para uma 'marginalidade' destruidora ou opressora dos valores humanos - a película de António Reis reveste-se de importantíssimo significado. Jaime, aquele 'recluso' entre tantos 'reclusos' de um hospital do tipo dos que o vulgo ainda chama 'manicómios', era um poderoso artista... (Soares apud Moutinho; Lobo, 1997: 140).

Pensar o caso de Jaime Fernandes a partir destas narrativas traz uma série de questões sobre a formação de um imaginário em torno do "mestre esquizofrênico". Ideia esta desenvolvida pelo psiquiatra e crítico de arte Hans Prinzhorn'12 (1886-1936), que prevê a existência de um instinto de criação na imaginação esquizofrênica, mais tarde reavaliada pela noção de art brut de Jean Dubuffet.

Mais do que isso, a ideia de "mestre esquizofrênico" de Prinzhorn propõe que, sujeitos asilados produzem a partir de princípios e valores muito particulares, em suma: criam seus próprios conceitos e significados; unificam sua produção em torno de uma ideia (que pode ser entendida como um delírio); na maioria das vezes, criam características estéticas particulares; e, repetem conceitos e ideias assim como modelos estéticos em suas obras. Estas qualidades projetam uma diferenciação entre os sujeitos esquizofrênicos que criam obras de interesse artístico de outros que apenas expressam emoções e ideias, mas não possuem qualidades estéticas. Para atingir tais efeitos, Prinzhorn estimulava o estudo de pacientes que haviam produzido isoladamente, sem contato com os ensinamentos da arte ou mesmo sem estímulos externos:

The persons who produced our pictures are distinguished by having worked more or less autonomously, without being nourished by the tradition and schooling to which we attribute the majority of more customary works of art... The configurative process, instinctive and 
free purpose, breaks through in these people without any external stimulus or direction they know not what they do... Nowhere else do we find the components of the configurative process, which are subconsciously present in every-man, in such an unadulterated state (...) Tradition and schooling can influence the configurative process only peripherally, by promoting, through praise and reproach, rules and systems. There is, however, a kind of intrinsic process; the preconditions for its development are present in every person... When the configurative instinct emerges spontaneously in mentally ill persons after years of hospitalization... an ability common to all men which usually remains latent or withered is suddenly activated (Prinzhorn [1922], 1995: 269-270) ${ }^{13}$.

Jaime seria, nestes termos, um autêntico "mestre esquizofrênico" ou mesmo um ótimo caso para a art brut. Tal como apontado por Cordeiro, uma psicose não medicada o teria levado a desenhar subitamente, o que garante a autenticidade e subjetividade da obra; viveu isolado por mais de 30 anos e possui um conjunto muito homogêneo de obras, ou seja, com uma forte narrativa estética que acompanha toda a sua produção. Tanto no filme quanto nas entrevistas não se fala especificamente em termos de art brut ou outsider art, mas é levantada uma série de qualificativos que, intencionalmente ou não, está intrinsecamente ligada a estes conceitos. Para ser mais exata, o conceito de art brut se funda sob alguns ideais sobre quem é o sujeito criador e, para isso, tem por norma a análise de alguns pontos, que também aparecem no filme sobre Jaime Fernandes, tais como: breve histórico biográfico (logo na abertura do filme); obra diretamente fundamentada na vida psíquica do artista ("nunca consegui ver Jaime pintor separado do homem"); ter iniciado as expressões após o internamento e em idade tardia (já aos 65 anos); ter em praticamente todas as suas obras uma continuidade estética ou um diálogo formal ("há um contraponto entre pintura animalista e o humano, as figuras animalistas são os arquétipos do campo..."); a destituição do preciosismo dos grandes artista em benefício da simplicidade ("certa crueza da observação"); e, na maior parte dos casos, ter tido uma psicose ("o Jaime era uma esquizofrênico paranoico") ${ }^{14}$.

Antes de mais, é preciso compreender que o ideal de "mestre esquizofrênico" reúne os elementos fundantes para o futuro conceito de art brut e suas variações, como a outsider art, elevando a arte dos doentes mentais a um patamar de distinção, teórica e estética: com relação a arte dos "homens normais", mas também de distinção ao ideal da "arte dos loucos" como uma expressão sem sentido e sumariamente extensiva ao organismo do sujeito que a produziu'15. Mas, há algo a mais: Prinzhorn faz questão de separar os "mestres esquizofrênicos" daqueles que simplesmente produzem, por instintos, expressões de todos os tipos. Quer dizer, todos os seres humanos criam, mas apenas alguns criam obras de arte e no universo dos esquizofrênicos isso não se difere.

Depois de dizer que a epilepsia saiu de moda entre os psiquiatras ${ }^{16}$, Prinzhorn afirma que agora (na década de 1920) é a vez da esquizofrenia que, no que tange às expressões, tem uma rara vantagem: a riqueza e abundância na variedade de formas. Este "trunfo" da esquizofrenia não é, de modo algum, um mero acaso. Pelo contrário, a ideia introduzida por Eugen Bleuler (1857-1939) é a de um grupo de psicoses que se caracteriza pela cisão da personalidade com a realidade. Nestes casos, é notável a alteração dos sentidos, dos modos do pensamento e de se relacionar com o exterior, reverberando na forma como o sujeito age em sociedade, como se expressa e como demonstra seus sentimentos. Características que Bleuler resumiu em três sintomas típicos: a ambivalência, a associação cindida e o afeto inadequado. $\mathrm{E}$ o mais importante: a partir do momento em que se verifica nas doenças mentais a subjetividade, o comportamento e o arbítrio - ainda que cindidos da realidade - um novo rol de possibilidades se abre sobre seus modos de agir e de expressar o mundo:

Ao transformar a definição de Kraepelin num conceito psicodinâmico, a obra de Bleuler inaugura uma psicopatologia nova e marca uma transição: da era das classificações 
("etiológicas", ou "sintomáticas", ou "nosológicas") que supunham a loucura como um mosaico de quadros estáticos, delimitáveis e unitários, para uma era em que tais diferenças só interessam no enfoque clínico do caso particular concreto e, mesmo assim, secundariamente. $O$ que passa a contar, para a explicação da doença (ou de qualquer quadro dela), é a identificação dos processos psicodinâmicos subjacentes. É deles que resulta a diversidade sintomática, a variada suscetibilidade aos diferentes fatores causais e o decurso da doença (Pessotti, 1999: 173).

Isto possibilita dizer: a arte dos doentes mentais não é apenas garatujas de um organismo doente, mas expressões de forte cunho emocional e que remetem a universos particularizados tanto no que diz respeito à forma quanto ao conteúdo: "As such, they serve to free the creator from emocional conflicts. With these works we are exposed to creation in its pure state - raw and reinvented in all its phases by the impulse-driven artists..." (Schreiner, 1988: 13) ${ }^{17}$.

\section{Um outsider na Fundação Calouste Gulbenkian}

Seguindo a deixa aberta pelo filme de Reis e Cordeiro, a Fundação Calouste Gulbenkian preparou uma exposição, já em 1980, com o mesmo nome, Jaime. A mostra apresentou 74 obras de Jaime Fernandes Simões em papel, realizadas com esferográfica ou lápis e em dimensões pequenas (figs. 3 e 4). No catálogo publicado, uma série de imagens impressas em preto e branco nos ajudam a perceber o forte diálogo estético e de conteúdo em seus desenhos: saltam aos olhos as cabeças unidas a corpos de animais, formando um só ser, feitas com um emaranhado de riscos, como uma teia que dá forma às figuras. Seus desenhos, colocados lado a lado, parecem seguir uma única narrativa. Não foram expostos os textos que, no filme, ganharam destaque.

João dos $\operatorname{Santos}^{18}$ (1913-1987) assina a apresentação do catálogo da exposição com o título É talvez abusivo expor Jaime. E expor Jaime é abusivo, para Santos, porque: "Jaime não é um filme, não é só uma obra. Jaime somos nós, vistos por dentro, numa profundidade que desconhecemos" (1980, s/p). É preciso lembrar que este texto é de um psicanalista. As teias que dão forma aos desenhos de Jaime são compreendidas por João dos Santos como um complexo orgânico que o limitam, num sentido de aprisionamento da mente. $\mathrm{O}$ autor segue por uma narrativa que busca encontrar elos dos homensanimais de Jaime com a pré-história ou traços primitivos. É pelo desenho, repetitivo e em traços contínuos, que João dos Santos encontra a redenção de Jaime, como um "mundo interior de liberdade, da liberdade que porventura outros Ihe tiraram, e exterioriza o seu saber de homem solitário" (Ibidem). João dos Santos segue costurando palavras na busca de compreender a atitude expressiva daqueles desenhos. Sobretudo, para ele, são traços que representam ou objetificam o medo, a angústia, que fazem com que estes fantasmas se tornem uma realidade dentro da obra materializada: "o mais terrível dos medos é o medo sem objeto, é a loucura" (Ibidem). Em suma, a construção plástica de Jaime Fernandes seria um autorretrato porque toda arte o é:

Tudo quanto exprimimos pelo gesto, pela palavra ou pela expressão plástica tem que ver com a nossa loucura mais ou menos elaborada; tudo quanto escrevemos, desenhamos ou pintamos, é auto-retrato mais ou menos retocado. A obra de Jaime é auto-retrato. Ela exprime o que fizeram dele o seu mundo infantil e a sociedade dos homens e o que ele próprio fez de tudo isso (Santos, 1980, s/p). 

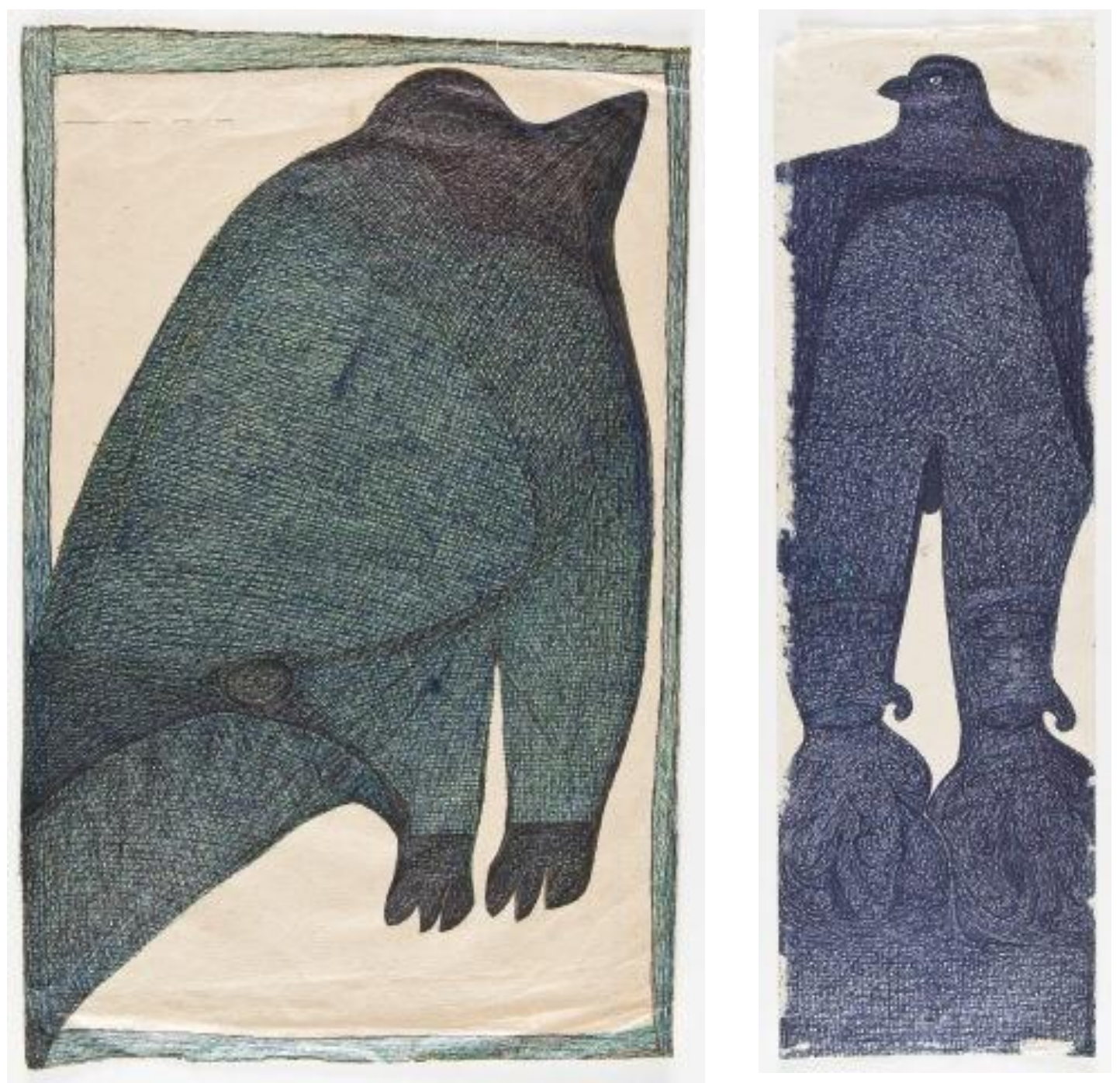

Fig. 3 e 4. Jaime Fernandes, (sem título), (sem data). Esferográfica sobre papel. ( $31,6 \times 49,2),(43,9 \times 13,5)$. Pertencentes à Fundação Calouste Gulbenkian. Disponivel em <https://gulbenkian.pt/museu/artist/jaime-fernandes/>.

João dos Santos apela, por fim, para que se respeite a "intimidade provavelmente desvendada" de Jaime Fernandes. $O$ que roga aos visitantes da exposição é que apenas contemplem o modo criativo de significar a sua subjetividade, porque na busca de desvendar a loucura de Jaime, "se arriscam a desvendar a vossa"(Ibidem).

O segundo texto do catálogo é assinado por Fernando de Azevedo (1923-2002). Seu texto vai por um caminho muito parecido ao de João dos Santos, que é o sentido da materialização dos sonhos, dos medos, das angústias através da expressão plástica. A lembrar que tais semelhanças não se dão por acaso: foi Fernando Azevedo um dos principais colaboradores do surrealismo português ${ }^{19}$. Do mesmo modo que o psicanalista, o artista compreende a criação plástica de Jaime como uma luta constante com as dores que 0 aflige: "É assim porque é puro. É assim, porque o seu combate com o demoníaco é uma inconsciente busca de verdade, um trabalho tremendo de humanizar as forças que 0 arrastam para o não existir, que o amarram, hora a hora, por fora do tempo à sua própria ausência" (Azevedo, 
1980, s/p). Fernando Azevedo, entretanto, vai mais além e busca, na contramão do que sugeria João dos Santos, uma interpretação íntima de Jaime:

Talvez, por tudo isso, nos desenhos de Jaime, à dispersão labiríntica e errante dos sentidos na sua simbólica imediata da libido, se oponha uma concentração conduzida, ordenada, verdadeiramente uma construção. Um espaço imaginário sim, mas em que cada elemento além do premente pretexto simbólico do seu aparecimento tem, sobretudo, pela decisão da forma, pelo seu ritmo, pela organização da cor, a exigência de como se situar e relacionar naquele espaço imaginário (Ibidem).

Algo interessante ainda de se notar é que é referido em seu texto a terapêutica como um caminho que teria levado Jaime a este regresso íntimo, de autoconhecimento ou de materialização de seu sofrimento. $\mathrm{E}$, como que premeditando o que diriam os mais conservadores da art brut, Azevedo afirma que não há contradições neste movimento, pelo contrário: este teria sido o modo de colocar em "relação (ou choque) o submundo concentracionário e o mundo externo" e, de modo algum, seria uma "referência mecanizada" (Ibidem). Não faltava, portanto, os elementos mais "crus", mais "virginais" ou mais "puros" de sua atitude expressiva. Ainda sobre isso, e para fechar, define: "... Jaime é inocência. Sabedoria e inocência são os dois contrários que Jaime torna unos numa experiência humana que tem por fundo 0 drama da solidão e do afastamento da vida" (Ibidem). De fato, é preciso considerar que Jaime ficou mais de 30 anos internado em uma instituição que ainda atendia pelo nome de "manicômio", não havia ali muitas alternativas para uma culturalização nos termos que nos fala Jean Dubuffet.

Dubuffet partia do princípio de que o artista conhecedor das convenções e técnicas artísticas projetava um modo de pensar sobre a sua expressão artística que seria sempre uma visão tecnicista e cultural. Assim, questiona: como os sujeitos não conhecedores de tais técnicas projetam seus pensamentos para se expressar? Do mesmo modo que seus colegas de vanguarda, em especial os surrealistas, Dubuffet parecia consciente de que ele próprio não produziria uma pintura a partir de uma psicose esquizofrênica - ou seja, o máximo que poderia ele (um artista cultural) chegar era à experiência de determinadas possibilidades estéticas, no sentido de que estas possibilidades o levariam a recodificar a sua própria forma de pensar a arte. Em suma, as obras da coleção de art brut retratam as expressões do pensamento, antes de se projetarem enquanto arte para o mundo (Dubuffet, 1949).

A exposição na Fundação Calouste Gulbenkian teve um papel importante na propagação e fruição de discursos, assim como em estabelecer um debate sobre as práticas artísticas e a doenças mentais. $\mathrm{E}$ é neste sentido que a exposição eleva Jaime ao estatuto da art brut, mesmo sem dar muitas considerações teóricas a respeito. Afinal, como Fernando Azevedo tratou, quase trinta anos antes: "a arte não resolve problemas, mas sugere novos problemas" (A.S.O., [1952] 1992: 8) ${ }^{20}$. Jaime Fernandes impulsiona o "problema" da art brut em território português a partir do momento em que seus desenhos encontram discursos teorizantes e tão complexos quanto as figuras que compunha. Quer dizer, a definição de art brut carrega consigo uma teia de sentidos que se encontra com a história nosográfica da esquizofrenia e possibilita aos críticos e teóricos da arte elevar aquilo que era anteriormente concebido enquanto a extensão de um corpo doente à projeção artística. É, diga-se de passagem, apenas na instituição da art brut enquanto conceito artístico que as expressões dos sujeitos acometidos por doenças mentais entram para as galerias, museus, mercado da arte e dos colecionismos sem arrastar consigo o peso da degeneração mental.

\section{A internacionalização de Jaime: o primeiro outsider português}

A mostra de Jaime na Fundação Calouste Gulbenkian, a exemplo disto, seguiu parcialmente para a $16^{a}$ Bienal de São Paulo, com 50 obras. Algumas notas sobre esta mostra são importantes. A $16^{a}$ Bienal 
representa uma viragem tanto no formato ou na estrutura da mostra quanto em seu conteúdo expositivo. A começar, esta é a primeira vez que se assume uma curadoria geral, assinada por Walter Zanini (19252013) ${ }^{21}$, e se dilui o formato de agrupamento por países, optando por uma abordagem que priorizava a relação entre linguagens comuns. Havia, assim, quatro grandes seções que compunham o total da mostra: cinema; video art; arte postal e arte incomum. Como já é possivel imaginar, as obras de Jaime Fernandes foram encaminhadas à esta última seção, que teve a curadoria de Annateresa Fabris, Victor Musgrave e Josette Balsa. Por "arte incomum", os curadores compreendiam algo muito próximo à art brut de Dubuffet: "à margem do sistema da arte cultural (...) expressões reveladoras de cosmogonias absolutamente pessoais (...) espontaneidades de invenção não-redutíveis a princípios culturais estabelecidos" (Zanini, 1981: 7).

Nas palavras de Musgrave, para o catálogo, há uma tentativa de definir termos como "arte incomum", art brut ou outsider art separando-as em contextos específicos, mas são praticamente sinônimas sendo por outro lado diferenciadas da arte de contextos terapêuticos e o que o próprio chama de "arte tribal". Para ser um outsider, ainda seguindo as pistas de Musgrave, é preciso criar uma "cosmogonia" própria. Entre os selecionados para a mostra, estavam os grandes mestres da art brut: Scottie Wilson, Adolf Wölfli, Le Facteur Cheval, Alöise Corbaz, Anton Müller, Madge Gill, além de representantes brasileiros do ateliê de Nise da Silveira e do Hospital do Juquery. E, pela primeira vez em uma mostra internacional a representar a art brut portuguesa, estavam os desenhos de Jaime Fernandes. Como síntese das ideias dos curadores sobre a "arte incomum", cito as palavras de Annateresa Fabris:

Para explicar essas visões particulares, essas formas que parecem desafiar a história por representarem imagens desde sempre presentes no homem, seria mais fácil recorrer à terminologia estilística corrente. Mas que sentido teria falar em gótico, barroco, expressionismo, fauvismo, primitivismo, art nouveau, e assim por diante, se o que devemos buscar nessas expressões é o gesto primeiro, é a gênese da criação, que não hesita em sujar suas mãos de barro e tinta, em trabalhar com os instrumentos mais rudimentares, em inventar novas técnicas, porque o que importa é transmitir ao mundo a própria mensagem, de qualquer maneira, em qualquer suporte? (apud Zanini 1981: 24)22.

O texto de apresentação de Jaime Fernandes no catálogo da mostra é o mesmo que Fernando Azevedo havia escrito para a exposição da Gulbenkian. No momento destas exibições, as obras de Jaime Fernandes pertenciam, em sua maioria, a coleções privadas que de algum modo estiveram ligadas à cena hospitalar. Após a filmagem de Reis e Cordeiro, as obras foram depositadas na Fundação Calouste Gulbenkian, pois já na altura discutia-se a intenção de realizar uma exibição com as mesmas. Segue-se que, três anos após a exposição, a Fundação optou por comprar quatro dos desenhos expostos ${ }^{23}$, mais precisamente quatro animais de Jaime feitos à esferográfica. As obras começaram a se espalhar por colecionadores especializados em art brut, dentre os quais: Collection de L'Art Brut e Eternod-Mermod Collection, ambas em Lausanne; ABCD Art Brut, em Montreuil [figs. 5 e 6]; Christian Berst Art Brut, em Paris; Coleção Treger/Saint Silvestre, em Portugal; Gérard Schreiner e John L. Notter, em Nova York; Hannah Rieger collection, em Vienna; Karin and Gerhard Dammann Collection, em Tägerwilen. À parte destas coleções, ainda há duas obras no acervo do Hospital Miguel Bombarda ${ }^{24}$.

Para conseguir fechar o caso Jaime Fernandes lembro que, já em 1997, Michel Thévoz escreveu um texto sobre ele para a revista L'Art Brut25, consagrando-o em definitivo como um artista do gênero. Em suma, o texto faz um aparato biográfico e a referência de algumas obras da própria coleção de Lausanne, como é de praxe nas apresentações desta revista. Thévoz, partindo dos princípios mais fiéis da art brut, cria um imaginário das expressões de Jaime que é possibilitado pela união entre a 
forma e o conteúdo de suas obras, em diálogo com a sua trajetória de vida. Quero diz<er, quando se fala em art brut, de modo geral, aquilo que se representa (o conteúdo) está estreitamente ligado ao modo como se representa (a forma), buscando sempre este elo entre o estilo e o significado íntimo da obra. Claro que tais escolhas não são de Jaime - afinal nunca o ouvimos teorizar sobre seus desenhos - mas de um discurso criativo que torna possível um universo hermético a partir das possibilidades a que a linguagem artística lhe permite. Sobre Jaime, nas palavras de Thévoz:

Ce qui frappe immédiatement dans les dessins de Jaime, c'est l'emprisonnement des personnages dans une trame linéaire serrée et inextricable. Dans bien des cas, les figures s'amalgament au point de fusionner. Le cavalier ne fait qu'un corps unique, des visages émergent d'une masse indifférenciée comme s'il s'agissait d'un seul organisme polycéphale. Et quand il se trouve seul, le personnage ou l'animal s'enlise dans son propre corps, un corps sans organes - moins qu'un corps en définitive: une sorte de coagulation de l'espace, une entropie dans laquelle l'être se trouve aplati, évidé, pour ainsi dire, ou aspiré comme l'eau par le trou trou d'un évier. On en arrive au minimalisme extrême, à la limite de la raréfaction des informations, mas justement, une raréfaction qui mobilise notre attention au plus haut degré. C'est le principe même d'individualité qui paraît ainsi menacé par le réseau arachnéen des fils d'encre ou des hachures de crayon, comme si la figure trouvait dans son propre tracé non pas un support expressif mais une force adverse, non pas une affirmation mais une négation. Parfois la figure insiste néanmoins éperdument, en tentant de se multiplier, mais c'est alors, en sens inverse, la duplication, la répétition ou le clonage qui produisent le même effet d'annihilation de la singularité (Thévoz, 1997: 6-7)26.
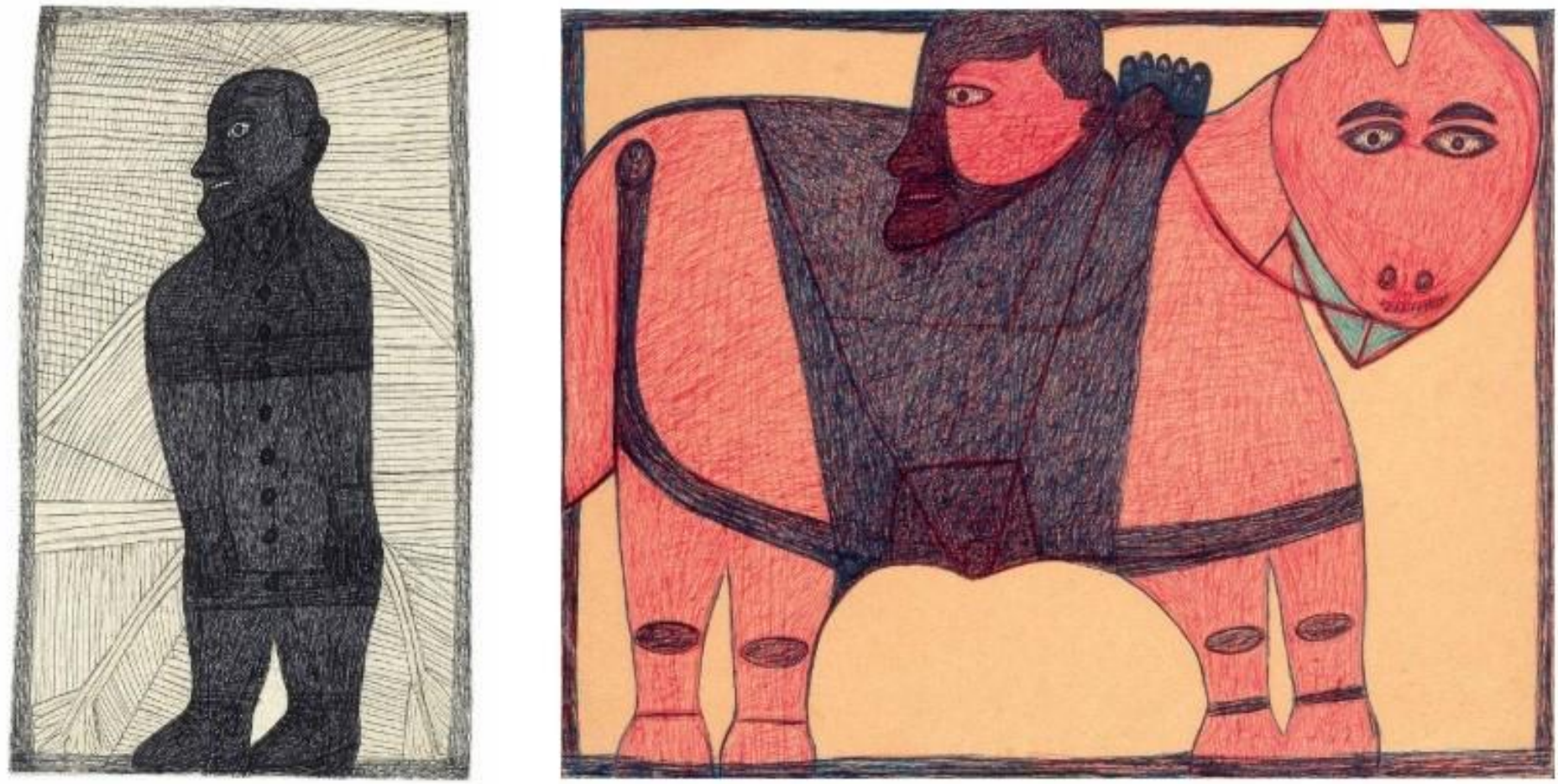

Figs. 5 e 6. Jaime Fernandes, (sem título), (sem data). Esferográfica sobre papel. (32 x 19), (sem informação), (Pertencentes à ABCD Art Brut Collection. Disponível em: <https://abcd-artbrut.net/en/collection-en/fernandes-jaime/>.

Se há algo que a art brut proporcionou às artes e que se perpetua até os dias de hoje é esta imagem mental como algo potencialmente criativo e artístico. Dubuffet, ao criar um conceito ao amontoado de obras de sua coleção, não buscava aprender a pintar com os loucos e naïfs - ou seja, sua intenção não era coisificar a forma "primitiva" numa estética possível para as artes -, antes, propunha imaginar como 
estes sujeitos pintavam, através de quais efeitos criativos: "pintar um rosto como se pinta uma maçã... ah não! O pensamento está intimamente ligado à descrição; se eu pinto as orelhas, estou a pensar no barulho, se pinto os lábios, estou a pensar nas palavras, se pinto os dentes, nos alimentos" (Dubuffet apud Jaeger, 2000: 18). Ao dizer isto, Dubuffet não estava apenas a tratar do desvio da forma, mas, em amplo sentido, do desvio do pensamento que leva à forma "primitiva". Dubuffet partia do princípio de que 0 artista conhecedor das convenções e técnicas artísticas projetava um modo de pensar sobre a expressão artística que, em sua concepção, era sempre uma visão tecnicista e cultural. Saindo deste princípio é que questiona: como os sujeitos não conhecedores de tais técnicas projetam seus pensamentos para se expressarem?

Quando nos deparamos com a descoberta de um artista brut, há sempre um grande esforço narrativo sobre as qualidades de sua obra e, claro, uma tentativa explícita de relacionar sua biografia com a estética ou a temática das obras. Daí reside a importância ou a frequente narrativa biográfica sobre os sujeitos outsiders, porque é ela que garante a inocuidade das expressões em relação aos meios culturais da arte:

With painting in general, the biography of the artist does not contribute to the understanding of the work, except in rare cases. For Outsider artists, it is the opposite. Each artists imposes his or her particular emotional past on the forms and colors. One might say that each artist has a special symbolic language, a unique handwriting ${ }^{27}$ (Schreiner, 1988: 13).

É preciso comprovar que esta linguagem simbólica e esta "caligrafia única" justificam-se pelos domínios vividos do sujeito, tanto pelo seu gesto "esquizo" quanto pelo afastamento com a cultura e a sociedade. A art brut, neste sentido, se evidencia como um discurso que inaugura um sujeito entre as possibilidades herméticas da mentalidade "esquizo" e as possibilidades narrativas dos conceitos artísticos. Isso significa dizer que a art brut não é "um macaco a datilografar a ilíada" 28 , mas ela também não é um lirismo cru e virginal existente apenas na cabeça de um sujeito como Jaime Fernandes ou tantos outros.

Em outros termos, e para fechar, reconhecer a artisticidade da produção dos loucos, em tempo contemporâneo, é basicamente aceitar a loucura que a nossa sociedade produz. Quer dizer, entender a art brut como um delírio em si ou como uma produção pueril da natureza interna de um indivíduo é um tanto quanto simplório - e não considero que Jean Dubuffet a via deste modo. A art brut conforma, antes, uma tentativa de ajustar conceitualmente aquilo que parece desmembrado ou disperso ao campo das artes: a mentalidade esquizofrênica. É, portanto, algo instituído pela e para a política das artes.

Jaime Fernandes faz parte deste complexo de possibilidades analíticas que envolve políticas psiquiátricas e artísticas, mesmo sabendo pouco sobre sua biografia, mesmo boa parte de suas obras terem desaparecido. A potência de criação de um sujeito, dentro de um sistema asilar e sem pretensão de diálogo com os cânones da arte, provoca uma reação de espanto ainda nos dias de hoje e é isso que mantém a art brut enquanto um conceito operante e resistente: "they demonstrate to cultural insiders who they are by reminding them of who and what they are not"29 (Hall; Metcalf, 1994: xiii).

\section{Referências}

A.S.O. [1952]. Pequeno escândalo no Chiado: a arte não resolve problemas mas sugere novos problemas - dizem-nos três pintores surrealistas. In: Colóquio . - Lisboa . - S. 2, a. 34, n. 94. (Set. 1992), p. 8.

AZEVEDO, Fernando. Os desenhos de Jaime. In: FUNDAÇÃO CALOUSTE GULBENKIAN.
Jaime. Lisboa: Fundação Calouste Gulbenkian, 1980, s/p.

BOURDIEU, Pierre. As regras da arte. Gênese e estrutura do campo literário. São Paulo: Companhia das Letras, 1996.

COELHO, Eduardo Prado. Vinte anos de cinema português (1962-1982). Lisboa: Instituto 
de Cultura e Língua Portuguesa, 1983. (Coleção Biblioteca Breve, vol.78).

COLÓQUIO. ARTES. Revista De Artes Visuais, Música E Bailado. Lisboa . - S. 2, A. 34, n. 94 (Set. 1992).

DUBUFFET, Jean. L'art brut préféré aux art culturel. Paris: Galerie René Drouin, 1949.

Notices sur la Compagnie de L'Art Brut. Cidade : Editora, 1948.

Prospectus et tous écrits suivants. Paris: Gallimard, 1967 (tomo 1).

FRANÇA, José Augusto. Dubuffet, 'o bad'. Diário de Lisboa. Lisboa, p. 3, 8 jun.1985.

"Jaime". In: Colóquio das Artes, Lisboa, n. 47, 2ª série, $22^{\circ}$ ano, p. 71, dez.1980,.

FROIS, João P. 'Animals portrayed as princes': the ballpoint-pen drawings of Jaime Fernandes. Epidemiology and Psychiatric Sciences, Cambridge, n.25, p.211-213, 2016.

The Bestiary Art of Jaime Fernandes. Raw Vision, n. 90, p. 30-34, 2016a.

\section{FUNDAÇÃO CALOUSTE GULBENKIAN.} Jaime. Lisboa: 1980.

HALL, Michael D. \& METCALF, Eugene W. The artist outsider: creativity and boundaries of culture. Washington: Smithsonian Institution Press, 1994.

JAEGER, Frédéric. As metamorfoses do homem comum. In: CULTURGEST. Jean Dubuffet. Lisboa: Culturgest, 2000.

JAIME. Direção António Reis e Margarida Cordeiro. Lisboa. Centro Português de Cinema e Telecine-Moro. 1974 (37minutos).
MACGREGOR, John. M. The Discovery of the art of the insane. New Jersey: Princeton University Press, 1989.

MOUTINHO, Anabela; LOBO, Maria da Graça. António Reis e Margarida Cordeiro: a poesia da terra. Faro: Cineclube de Faro, 1997.

PAREDES, Carlos [1974]. Jaime. In: MOUTINHO, Anabela; LOBO, Maria da Graça. António Reis e Margarida Cordeiro: a poesia da terra. Faro: Cineclube de Faro, 1997.

PESSOTTI, Isais. Os nomes da loucura. São Paulo: Editora 34, 1999.

PRINZHORN, Hans [1922]. Artistry of the mentally ill. A contribution to the psychology a psychopathology of configuration. New York/ Wien, Allemagne: Springer-Verlag, 1995.

SANTOS, João dos. É talvez abusivo expor Jaime. In: FUNDAÇÃO CALOUSTE GULBENKIAN. Jaime. Lisboa: Fundação Calouste Gulbenkian, 1980, s/p.

SCHREINER, Gérard (edit.). Outsiders, a collection of art brut. Vol. I. New York: Editora, 1988.

SOARES, Fernando Luso. Jaime. In: MOUTINHO, Anabela; LOBO, Maria da Graça. António Reis e Margarida Cordeiro: a poesia da terra. Faro: Cineclube de Faro, 1997.

THÉVOZ, Michel. Jaime Fernandes. In: L'art brut. Gèneve: Editions d'Art Albert Skira, 1997, p.5-13.

L'art brut. Genève: Albert Skira, 1975.

ZANINI, Walter (curador geral). Art Incomum. $16^{a}$ Bienal de São Paulo. São Paulo: Fundação Bienal de São Paulo, 1981. Disponível em: em http://www.bienal.org.br/publicacoes/2129.

Acesso em: 04 ago. 2020.

\section{Notas}

\footnotetext{
* No ano de 2019 concluiu o doutorado em História da Arte na Universidade Nova de Lisboa com o projeto de pesquisa: "Os imperativos da arte: encontros com a loucura em Portugal do século XX". Possui mestrado em Antropologia Social pela Faculdade de Filosofia, Letras e Ciências Humanas da Universidade de São Paulo (FFLCH/USP/2011) e graduação em Ciências Sociais pela Fundação Escola de Sociologia e Política de São Paulo (FESPSP/2008). Como foco de interesse tem percorrido temas relacionados à institucionalização da loucura, as práticas nosográficas da psiquiatria, assim como a promoção da loucura como elemento discursivo no campo das artes. E-mail: <steffranco@gmail.com>.ORCID: <https://orcid.org/0000-0003-1091-0908>.

${ }^{1}$ Entrevista com João César Monteiro, originalmente publicada no Cinéfilo, n. ${ }^{0} 29$, págs. 23-32, de 20 de abril de 1974. Disponível em $<$ http://antonioreis.blogspot.com/2004/10/037-jaime-entrevista-por-joo-csar.html>. Acesso em: 06/08/2020.

2 "Jaime Fernandes veio de uma família de uma aldeia do interior de Portugal, e viveu uma vida que era comum para pequenos agricultores em que a sua subsistência dependia de boas ou más colheitas anuais. Ele foi o primeiro dos três filhos de Joaquim Fernandes e Maria de Jesus, nasceu a 8 de maio de 1899, em Barco, uma pequena aldeia do distrito da Covilhã, $300 \mathrm{~km}$ a norte de Lisboa. Em 1923 casou com Evangelina Delgado, com quem teve cinco filhos..."

${ }^{3}$ Consultado sob autorização do Conselho Administrativo do Centro Hospitalar Psiquiátrico de Lisboa (CHPL) em 2016.
} 
${ }^{4}$ Uma boa parte das informações que surgem em meio à história de Jaime Fernandes é encontrada em catálogos, artigos de jornais, entrevistas, mas não possuem outras referências ou outros tipos de fontes documentais. Por isso, a história de Jaime - como da maior parte dos artistas outsiders - possui muitos "diz-se" ou "sabe-se", porque são conhecimentos narrados por médicos, enfermeiros, pela família e mesmo pelos pesquisadores que se debruçaram sobre a sua história.

${ }^{5}$ Não se pode dizer que, com Jaime, alimentou-se um debate sobre os artistas brut ou outsiders no país. Pelo contrário, estas noções custaram muito a se desenvolver em solo português e apenas nos últimos anos é que o tema da art brut, já muito longe de ser algo inédito, começou a ter interesse em termos curatoriais ou de investigação.

${ }^{6}$ António Reis e Margarida Cordeiro produziram quatro filmes juntos: Jaime (1974), Trás-os Montes (1976), Ana (1982) e Rosa de Areia (1989). Uma breve pontuação: Margarida Cordeiro é médica com especialização em psiquiatria e trabalhou conjuntamente com António Reis na montagem de todos os filmes, como a própria diz em entrevista: "eu sou 100\% realizadora em cada filme e ele outros 100\%" (Cordeiro, 1997: 13).

${ }^{7}$ Entrevista de Margarida Cordeiro à Anabela Moutinho (1997).

${ }^{8}$ Artigo da revista Celulóide, n. 204, dez. 1974. In: (Moutinho; Lobo, 1997: 242).

${ }^{9}$ Entrevista de António Reis a João César Monteiro.

${ }^{10}$ Estas frases aparecem em legenda, ao se atentar à grafia de Jaime, lê-se: "8 Veizez. Jaimez môurreja" ou algo próximo a isso.

11 Todos estes termos em aspas foram retirados de artigos e notas publicadas sobre o filme (In: Moutinho; Lobo, 1997).

12 Não pretendo, aqui, fazer uma revisão das teorias sobre as expressões dos doentes mentais. Mas, certamente, Prinzhorn não foi 0 único e nem o primeiro a teorizar a respeito. Contudo, pode-se dizer que no início do século XX começa a se formar uma espécie de "crítica de arte dos insanos", tendo Marcel Rèja (1873-1957), Walter Morgenthaler (1882-1965) e Hans Prinzhorn (1886-1933) como principais referências. Em especial, esta mudança conceitual está ligada à formação de teorias como a psicologia da forma, que possibilitam pensar as expressões dos doentes mentais como criatividade e não apenas como extensão de um corpo degenerado.

13 "As pessoas que produziram as nossas imagens distinguem-se por terem trabalhado mais ou menos autonomamente, sem serem nutridas pela tradição e escolas que nós atribuímos a maioria dos trabalhos de arte mais costumeiros... 0 processo configurativo, instintivo e de livre propósito, rompe através destas pessoas sem nenhum estimulo ou direção externa - eles não sabem o que fazem... Em nenhum outro lugar nós encontramos os componentes do processo configurativo, que são inconscientemente presentes em todos os homens, ao menos num estado não inalterado (...) Tradição e escolaridade podem influenciar o processo configurativo apenas perifericamente, promovendo, através de elogios e críticas, regras e sistemas. Há, no entanto, um tipo de processo intrínseco; as precondições para estes desenvolvimentos estão presentes em todas as pessoas... Quando 0 instinto configurativo emerge espontaneamente nos doentes mentais após anos de hospitalização... uma habilidade comum a todos os homens que geralmente permanece latente ou murcha é subitamente ativada"

${ }^{14}$ As citações entre parênteses deste parágrafo foram retiradas da entrevista de António Reis a João César Monteiro como um seguimento lógico do que estou descrevendo (Reis, 1997: 242-257).

15 Prinzhorn, ao propor uma análise formalista e subjetivista, debruçando-se sobre casos modelos, eleva as expressões dos doentes mentais a uma categoria de experiência particular, resultando, em alguns casos, em formas autênticas e livres de associações sociais ou estéticas preestabelecidas.

${ }^{16} \mathrm{~A}$ epilepsia foi o grande tema dos médicos alienistas na instituição da psiquiatria enquanto ciência. Mais do que um sintoma ou uma doença, era uma degenerescência (Bombarda, 1896: VIII-IX). Tornou-se, igualmente muito conhecida pelas pesquisas desenvolvidas por Césare Lombroso (1835-1909) em sua teoria sobre o génio e a loucura.

17 "Como tal, eles servem para libertar o criador de conflitos emocionais. Com estas obras somos expostos à criação no seu estado puro - cru e reinventado em todas as suas fases por artistas a movidos pelos seus impulsos..."

${ }^{18}$ Médico psiquiatra e psicanalista, colaborou na criação da Sociedade Portuguesa de Psicanálise e no Centro de Saúde Mental Infantil. De fato, a atenção de João dos Santos estava na infância, tanto em termos de políticas assistenciais quanto em termos de pesquisa. Mostrou-se sempre contrário às grandes instituições asilares, indagando que a doença do paciente estava justamente no elo perdido com a sociedade e com as estruturas familiares.

${ }^{19} \mathrm{Em} 1947$, ajudou na fundação do Grupo Surrealista de Lisboa (GSL), junto a António Pedro, António Dacosta, Mário Cesariny, António Domingues, José-Augusto França, Moniz Pereira, Alexandre O'Neill e Vespeira. Ver: (Colóquio. Artes, 1992).

20 Originalmente em entrevista ao Diário de Lisboa, de 12 de janeiro de 1952, junto com seus colegas surrealistas Vespeira e Lemos. A matéria foi republicada na Revista Colóquio Artes, em 1992.

${ }^{21}$ Zanini era, na altura, ex-diretor do Museu de Arte Contemporânea da Universidade de São Paulo e estava muito relacionado à cena da video art, tendo colaborado com jovens artistas brasileiros na inserção desta área.

22 O itálico é da própria autora, mas relembro que esta ideia vem de Duchamp e já foi, aqui, mencionada anteriormente. Segue no catálogo importantes contribuições para o tema com textos de Jean Dubuffet sobre art brut; um texto introdutório sobre o trabalho no Engenho de Dentro, por Nise da Silveira; e, sobre Escola Livre de Artes Visuais do Juquery, por Annateresa Fabris; ainda há a reprodução de dois textos de Osório César $A$ inspiração artística entre os normais e os alienados (1948) e $A$ arte dos Loucos (1951). Para encerrar, um breve texto de Josette Balsa $A$ arte é um anti-destino e um texto sobre Wölfli, Aloise e Muller (1978), de Bridget Brown.

${ }^{23}$ Estas informações foram obtidas no "processo de exposição", consultado sob autorização junto à Fundação Calouste Gulbenkian.

${ }^{24}$ Estas duas obras estão expostas no Pavilhão de Segurança Máxima, mais conhecido como Panóptico, do já encerrado Hospital Miguel Bombarda.

${ }_{25}$ L'Art Brut Fascicles foi criada por Jean Dubuffet, em 1964, tendo como principais funções divulgar breves monografias sobre os criadores da art brut e a sua própria coleção.

26 "O que imediatamente impressiona nos desenhos de Jaime é o aprisionamento dos personagens em uma trama linear estreita e inextricável. Em muitos casos, as figuras se amalgamam no ponto de se fundirem. O cavaleiro forma um corpo único, os rostos emergem de uma massa indiferenciada como se fosse um único organismo policéfalo. E quando está sozinho, o personagem ou o animal está atolado em seu próprio corpo, um corpo sem órgãos - menos que um corpo em definitivo: uma espécie de coagulação do espaço, uma 
entropia dentro da qual o ser se encontra achatado, escavado, por assim dizer, ou sugado como a água pelo buraco de uma pia. Chegamos ao extremo minimalismo, no limite da escassez de informação, justamente, uma rarefação que mobiliza nossa atenção ao mais alto grau. É o próprio princípio da individualidade que assim parece ser ameaçado pela rede de linhas de tinta ou de traços de lápis, como se a figura encontrasse em seu próprio traço não por um suporte expressivo, mas por uma força oposta, não por uma afirmação, mas por uma negação. Às vezes, a figura insiste desesperadamente tentando se multiplicar, mas em seguida, na direção oposta, a duplicação, a repetição ou a clonagem produzem o mesmo efeito de aniquilação da singularidade."

27 "Com a pintura em geral, a biografia do artista não contribui para a compreensão da sua obra, excepto em casos raros. Para os artistas Outsider é precisamente o oposto. Cada artista impõe o seu passado emocional nas formas e cores. Podemos dizer que cada artista tem uma linguagem simbólica especial, uma caligrafia única".

${ }^{28}$ Tal como definiu Pierre Bourdieu, compreendendo a art brut como uma "arte não cultivada" que passa a existir no exato momento em que é descoberta e, apenas enquanto criação de seu "descobridor". ...assim constituída como arte sem artista, arte natural, surgida de um dom da natureza, ela proporciona o sentimento de uma necessidade miraculosa, à maneira de uma llíada escrita por um macaco datilógrafo, fornecendo deste modo sua justificação suprema à ideologia carismática do criador incriado" (1996: 278).

29 "Eles demonstram ao cultural insiders quem eles são relembrando-os quem e o que eles não são".

Artigo recebido em maio de 2020. Aprovado em agosto de 2020. 